\title{
Orbital swelling following peribulbar and sub-Tenon's anaesthesia
}

\author{
Eye (2004) 18, 418-420. doi:10.1038/ \\ sj.eye. 6700673
}

Keywords: orbital swelling; orbital cellulitis; proptosis; local anaesthesia; peribulbar block; sub-Tenon's anaesthesia

Orbital cellulitis has been reported following sub-Tenon's ${ }^{1,2}$ and peribulbar anaesthesia., Infection of the periorbital tissues, although not proven, was suggested as the most probable cause of cellulitis. We have encountered three other cases of orbital swelling during subTenon's and peribulbar anaesthesia, and we believe that reasons other than infection might have contributed to the condition.

\section{Case 1}

A 52-year-old male bus driver underwent left

${ }^{1}$ Academic Department of Anaesthesia

The James Cook

University Hospital

Middlesbrough, UK

${ }^{2}$ Department of Ophthalmology North Riding Infirmary Middlesbrough, UK

Correspondence: CM Kumar Academic Department of Anaesthesia

The James Cook University Hospital Middlesbrough TS4 3BW, UK Tel: + 441642854600 Fax: + 441642854246 E-mail: chandra.kumar@ stees.nhs.uk

Received: 13 February 2003 Accepted in revised form: 27 May 2003 phacoemulsification with a posterior chamber lens implant under sub-Tenon's local anaesthesia. Oxybuprocaine $0.4 \%$ eye drops were instilled before a single injection of $5 \mathrm{ml}$ of 2\% lidocaine and 1:200000 epinephrine with $1500 \mathrm{U}$ of hyaluronidase administered into the sub-Tenon's space through a 1 in curved metal cannula. The eye was then prepared with an aqueous solution of povidone-iodine $10 \%$ and routine phacoemulsification surgery was performed. At the end of the surgery, a subconjunctival injection of $75 \mathrm{mg}$ cefuroxime was given.

On examination the next day, his uncorrected visual acquity was 6/9 in the operated eye. Over the next 3 days, the patient developed marked chemosis and periorbital swelling. Oral antibiotics (amoxycillin $1 \mathrm{~g} 6$ hourly) and antihistamine (chlorpheniramine maleate $4 \mathrm{mg}$ twice daily) were prescribed, but despite the antibiotic and antihistaminic, the swelling continued to increase. On examination on the fifth day, there was $9 \mathrm{~mm}$ of axial proptosis with limitation of abduction and elevation movements. Visual acuity remained good at $6 / 9$ unaided with no afferent pupillary defect. The differential diagnosis included infective orbital cellulitis or an allergic reaction to the local anaesthetic or hyaluronidase. Further treatment was continued with ice packs, and the antibiotic was replaced by intravenous cefuroxime $1.5 \mathrm{~g} 8$ hourly. The patient remained apyrexial with a normal white cell count. CT and MRI scans showed pre- and postseptal inflammatory changes suggestive of orbital swelling or an evolving infection. Gradually, over 2 weeks, the lid swelling and chemosis settled and the eye movements improved. At 1 month after surgery, there was no residual proptosis.

\section{Case 2}

A 78-year-old man was admitted for a combined right phacoemulsification and glaucoma operation (viscocanalostomy). After topical oxybuprocaine $0.4 \%$ instillation, a peribulbar injection using a $27 \mathrm{G}, 2 \mathrm{~cm}$ long needle was introduced percutaneously in the extreme lateral inferotemporal area aseptically. ${ }^{5}$ A measure of $5 \mathrm{ml}$ of $2 \%$ lidocaine with $1: 200000$ epinephrine containing a total of $750 \mathrm{U}$ of hyaluronidase was injected. A supplementary medial transconjunctival peribulbar injection of $3 \mathrm{ml}$ of $2 \%$ with $1: 200000$ epinephrine containing $400 \mathrm{U}$ of hyaluronidase was administered. Good anaesthesia and complete akinesia followed. The eye was then prepared with an aqueous solution of povidone-iodine $10 \%$, and routine phacoemulsification surgery was performed. At the end of the surgery, a subconjunctival injection of $75 \mathrm{mg}$ cefuroxime was given.

On the first postoperative day, the visual acuity was 5/18 and the intraocular pressure was slightly elevated. Over the next 3 days, there was a marked periocular swelling and 
$5 \mathrm{~mm}$ of axial proptosis. Ocular movements were grossly limited. Vision had dropped to perception of light. There was a new right afferent pupillary defect. Treatment was commenced with ice packs, intravenous antibiotics (cefuroxime $1.5 \mathrm{~g} 8$ hourly), and glaucoma therapy (acetazolamide $500 \mathrm{mg}$ intravenously). A CT scan of the orbits showed pre- and postseptal swelling. He remained apyrexial with a normal white cell count. On this occasion, a rapidly reducing course of oral prednisolone (180 $\mathrm{mg}$ in three divided doses) was added. The combination of intravenous antibiotic and steroid led to a dramatic reduction in periocular swelling, proptosis, and intraocular pressure. Within 1 week of surgery, his visual acuity had recovered to $6 / 18$, although with a persisting afferent pupillary defect for slightly longer period.

\section{Case 3}

A 92-year-old male underwent left phacoemulsification with a posterior chamber lens implant under sub-Tenon's local anaesthesia. The same - anaesthetic and surgical technique as described in the first case was used. This patient also developed orbital swelling on the third postoperative day. He was apyrexial, blood tests were normal and the CT scan showed marked swelling of periorbital tissues and stretching of optic nerve. Intravenous antibiotic (cefuroxime $1.5 \mathrm{~g}$, 8 hourly) and prednisolone (180 $\mathrm{mg}$ in divided doses with a reducing dose) were started immediately after blood was taken for investigation. The patient recovered from the swelling within 3 days with no residual effect.

\section{Comments}

All three cases developed orbital swelling within a few days after local anaesthetic administration. We considered infection as a primary cause for the orbital swelling. In the absence of pyrexia and with entirely normal blood results, we had to consider other causes. On close scrutiny of the previously reported cases, and indeed in our cases, more than the recommended concentration of hyaluronidase was used. The British National Formulary (BNF) recommends $15 \mathrm{U} / \mathrm{ml}$ hyaluronidase for ophthalmic blocks. ${ }^{6}$ We considered the possibility of a drug-induced orbital inlamation (orbital pseudotumour) related to hyaluronidase. ${ }^{7}$ The clinical pictures presented in our cases appear to be consistent with this. However, a definitive diagnosis of this condition can only be made if orbital tissue is taken for biopsy and histology. Biopsy of orbital tissue was our next step, but we did not think it appropriate to pursue this invasive approach at the early stage. We were not entirely convinced that a drug-induced orbital inflammation was the cause in our cases, because there was no histological evidence.

At the time of occurrence of these cases, we were not aware of earlier reports of orbital swelling. Urgent emails to well-known ophthalmic anaesthetists and ophthalmologists in Canada, USA, and UK did not prove fruitful. Subsequently, these cases were presented to a mixed audience (anaesthetists and ophthalmologists) during the third Annual British Ophthalmic Anaesthesia Scientific Meeting in 2001. It became apparent during discussion that orbital swelling was not an isolated problem. Subsequently, the Committee of Safety of Medicine (CSM) was informed, but to date no further guidance has been issued.

We believe that infection was unlikely to be the causative factor in our cases, but this could not be completely ruled out. An excessive dose of hyaluronidase might well have played a part. We now routinely use hyaluronidase $15 \mathrm{U} / \mathrm{ml}$ mixed with local anaesthetic agent and since then we have not encountered any more cases. There are papers that suggest that there is little benefit to be gained from the use of hyaluronidase ${ }^{8,9}$ and there have been very rare descriptions of a true allergic reaction to hyaluronidase within the orbit. ${ }^{10,11}$ We believe that there is enough supportive data for the use of hyaluronidase, but would suggest that only the recommended amount of hyaluronidase, $15 \mathrm{U} / \mathrm{ml}$, should be used with local anaesthetic agent.

In the absence of a definitive diagnosis, we suggest that intravenous antibiotic and steroid should be started early for the treatment, and to prevent further progression, of orbital swelling.

\section{References}

1 Dahlmann AH, Appaswamy S, Headon MP. Orbital cellulitis following sub-Tenon's anaesthesia. Eye 2002; 16: 200-201.

2 Redmill B, Sandy C, Rose GE. Orbital cellulitis following corneal gluing under sub-Tenon's local anaesthesia. Eye 2001; 15: 554-556.

3 Varma D, Metcalfe TW. Orbital cellulitis after peribulbar anaesthesia for cataract surgery. Eye 2003; 17: 105-107.

4 Hofbauer JD, Gordon LK, Palmer J. Orbital cellulites after peribulbar injection. Am J Ophthalmol 1994; 118: 391-392.

5 McLure HA, Rubin AP, Westcott M, Henderson H. A comparison of $1 \%$ ropivacaine with a mixture of $0.75 \%$ bupivacaine and $2 \%$ lignocaine for peribulbar anaesthesia. Anaesthesia 1999; 54: 1178-1182.

6 British National Formulary. A joint publication of the British Medical Association and the Royal Pharmaceutical Society of Great Britain, London, 2002.

7 Kempeneers A, Dralands L, Ceuppens J. Hyaluronidase induced orbital pseudotumour as a complication of retrobulbar anaesthesia. Bull Soc Belg Ophthalmol 1992; 243: 159-166. 
8 Crawford M, Kerr WJ. The effect of hyaluronidase on peribulbar block. Anaesthesia 1994; 49: 907-908.

9 Alwitry A, Chaudhary S, Gopee K, Butler TK, Holden R. Effect of hyaluronidase on ocular motility in sub-Tenon's anesthesia: randomised controlled trial. J Cataract Refract Surg 2002; 28: 1420-1423.
10 Ahluwalia HS, Lukaris A, Lane CM. Delayed allergic reaction to hyaluronidase: a rare sequel to cataract surgery. Eye 2003; 17: 263-266.

11 Agrawal A, McLure HA, Dabbs TR. Allergic reaction to hyaluronidase after a peribulbar injection. Anaesthesia 2003; 58: 493-494. 